\title{
FATIGUE CHARACTERISTICS OF MATERIALS USED IN TRANSPORT INDUSTRY APPLICATIONS
}

doi: $\quad 10.2478 /$ czoto-2019-0104

Date of submission of the article to the Editor: $27 / 11 / 2018$

Date of acceptance of the article by the Editor: 14/01/2019

Juraj Belan ${ }^{1}$ - orcid id: 0000-0002-2428-244X

Lenka Kuchariková ${ }^{1}$ - orcid id: 0000-0002-2688-1075

Magdalena Mazur ${ }^{2}$ - orcid id: 0000-0003-3515-8302

Eva Tillová ${ }^{-}$- orcid id: 0000-0002-1010-0713

Mária Chalupová ${ }^{-}$- orcid id: 0000-0003-0175-9484

${ }^{1}$ University of Žilina, Faculty of Mechanical Engineering, Slovakia, juraj.belan@fstroj.uniza.sk

${ }^{2}$ Czestochowa University of Technology, Faculty of Management, Poland

Abstract: Designers have a major interest about fatigue properties of materials used in transport industry. Each component in transport works under alternating stress. From this point of view the fatigue properties are important for single parts lifetime resulting into safety of whole components as cars and airplanes what leads to safety on the roads or air and have influence on human life as well. Therefore this paper deals with fatigue properties of wrought Inconel alloy IN 718 and aluminum cast alloy AISi9Cu3. Both materials were put on fatigue push - pull test, but $\mathrm{Ni}$ - based IN 718 alloy at frequency of loading around $20000 \mathrm{kHz}$ (High Frequency High Cycles Fatigue) and aluminum alloy AISi9Cu3 at frequency of loading around $80 \mathrm{~Hz}$ (Low Frequency High Cycles Fatigue). These parameters were chosen with respect of usage such materials for production of components used in transport industry applications. Results after fatigue tests are presented as Wohler curve. For prediction of source of fracture the SEM fractography analysis of fatigue fracture surfaces was made.

Keywords: fatigue properties, Inconel alloy, aluminum alloy, fatigue fracture, transportation safety

\section{INTRODUCTION}

The progress in transport industry is enormous in past few decades. Cars become lighter and provide higher efficiency (breaking horse power or torque moment) with smaller engines - well known as "downsizing". Producing lighter automobiles, improving fuel efficiency, and improving vehicle performance have been some of the automobile industry's top challenges. The industry has done its research on material alternatives to steel such as carbon fiber and aluminum alloys. Aluminum alloys designed for automobiles weight half as much as traditional mild steel and absorb twice as much energy during accidents. The research shows the aluminum is the second - most used material in automobiles, and it 
has the potential to become the most used, as new aluminum alloys are made to deliver more value than steel (Kensington, 2015; Uhríčik, 2014).

The same situation is in aero industry, where using of aluminum alloys have also big importance, but for aero industry is limitation factor working temperature. The truth is, whenever superb design material aluminum alloys are, the limitation of their use temperature range up to $350^{\circ} \mathrm{C}-400^{\circ} \mathrm{C}$. When higher temperature application is needed, the $\mathrm{Ni}$ - base superalloys come in front of designers' interest. $\mathrm{Ni}$ - base superalloys as in opposite as aluminum alloys are due to its density $\left(\rho=8908 \mathrm{~kg} \cdot \mathrm{m}^{-3}\right)$ considered as heavy weight alloys. Superalloys keep its unique properties up to $700^{\circ} \mathrm{C}-800^{\circ} \mathrm{C}$ or even higher temperatures (above $1000^{\circ} \mathrm{C}$ what is almost $2 / 3$ rds of melting temperature $-1455^{\circ} \mathrm{C}$ ) when protective high - resistance surface layer is applied (e. g. alitize layer, TBC) (Kracke, 2010, Akca and Gursel 2015, Davis 2000).

For application in automotive and aero industries are more important the fatigue properties in terms of protecting about human life. Therefore the main object of this research work is studying fatigue properties of materials used for such applications. In this study, the fatigue properties of aluminum alloy AISi9Cu3 and of IN718 superalloy were investigated under push - pull low frequency (AISi9Cu3 alloy) and high frequency (IN 718 alloy) fatigue test at room temperature. With the help of scanning electron microscope (SEM), fractographic analyses were performed to disclose the fracture features of specimens in different life ranges.

\section{EXPERIMENTAL PROCEDURE}

The experimental materials are cast AISi9Cu3 alloy (prepared from recycled aluminum scrap, without modification, grain refined or heat treatment) delivered by company Confal a.s. (chill casting) in form of circular bars (dimension - $\varnothing 20 \times 300 \mathrm{~mm}$ ) and wrought $\mathrm{Ni}-\mathrm{Fe}$ - Cr base superalloy IN 718 delivered from BIBUS Metals Ltd. in heat - treated state (according to BIBUS Ltd. material sheet): $980{ }^{\circ} \mathrm{C} / 1 \mathrm{~h}$. AC + heating at $720{ }^{\circ} \mathrm{C} / 8 \mathrm{~h}$. followed FC $\left(50{ }^{\circ} \mathrm{C}\right.$ per hour) to temp. $620^{\circ} \mathrm{C}$ holding time $8 \mathrm{~h}$. and air cooled with final grain size ASTM 12. The chemical analysis of experimental samples was carried out using an arc spark spectroscopy at University of Žilina and are shown in Table 1.

Table 1.

Chemical composition of experimental materials (wt. \%)

\begin{tabular}{|c|c|c|c|c|c|c|c|c|c|}
\hline Elements & Si & Cu & $\mathbf{Z n}$ & $\mathbf{M g}$ & $\mathbf{F e}$ & $\mathbf{T i}$ & $\mathbf{S n}$ & $\mathbf{P b}$ & $\mathbf{A l}$ \\
\hline AISi9Cu3 & 9.4 & 2.4 & 1.0 & 0.28 & 0.9 & 0.04 & 0.03 & 0.09 & Bal. \\
\hline IN 718 & 0.09 & 0.03 & - & - & Bal. & 0.96 & - & - & 0.57 \\
\hline Elements & $\mathbf{C}$ & $\mathbf{C o}$ & $\mathbf{C r}$ & Mo & $\mathbf{N b}$ & $\mathbf{T a}$ & $\mathbf{M n}$ & $\mathbf{N i}$ & \\
\hline AISi9Cu3 & - & - & - & - & - & - & 0.24 & 0.05 & \\
\hline IN 718 & 0.026 & 0.14 & 19.31 & 2.99 & 5.30 & $<0.01$ & 0.07 & 53.32 & \\
\hline
\end{tabular}

Source: Own measurements

The low frequency high cycles (LFHC) fatigue tests of chill casted AISi9Cu3 alloy specimens were carried out using Vibrophores Amsler 50 - 250 HFP 5100 testing machine with symmetrical push - pull load (Fig. 1) and at room temperature of $20 \pm 5^{\circ} \mathrm{C}$. The high frequency high cycle (HFHC) fatigue experiments for IN 718 alloy were performed by ultrasonic push - pull method and appropriate cooling was used to avoid the temperature rise. Experimental fatigue machine KAUP - ŽU with loading frequency $20 \mathrm{kHz}$ was developed by Department of Material Science, Faculty of Mechanical Engineering, 
University of Žilina in Slovak Republic. Stress ratio of $R=-1$ was used for experiments. The specimen is in the shape of an hourglass.

The specimens for fatigue tests were extracted (by turning operation) from casted circular bars (dimension - $\varnothing 18 \times 150 \mathrm{~mm}$ ) - in the case of aluminum alloy and the bars with diameter of $12 \mathrm{~mm}$ for fatigue tests of wrought $\mathrm{Ni}$ - based superalloy. The fatigue fracture surfaces were examined using scanning electron microscope VEGA LMU II after testing in order to find the features responsible for crack initiation.

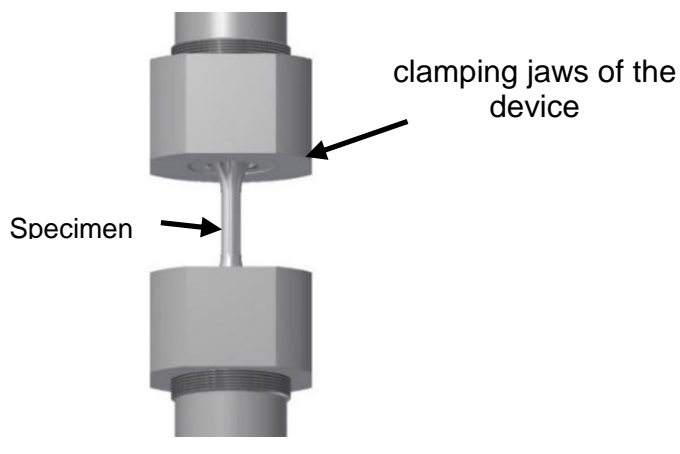

a) LFHC fatigue tests of AISi9Cu3

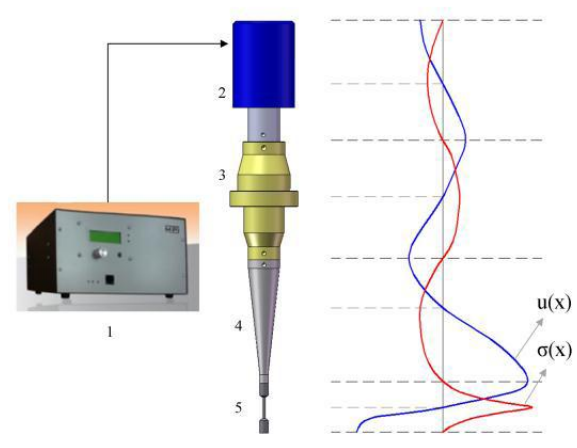

b) HFHC fatigue tests of IN718, 1 generator, 2 - piesoelectric actuator, 3 booster, 4 - horn, 5 - specimen

Fig. 1. The clamping scheme of fatigue samples

\section{RESULTS AND DISCUSSION}

\subsection{Fatigue test}

The results of fatigue tests carried out on samples extracted from experimental materials, are presented in the $\mathrm{S} / \mathrm{N}$ (stress amplitude vs. cycles to failure) diagram in Fig. 2. The number of cycles to be reached by the samples without breaking was $2 x$ $10^{7}$ for aluminium experimental material and $10^{8}$ for Inconel superalloy. The samples that reached these numbers of cycles without breaking are defined as run-out (red tetragon on Fig. 2). Obtained results were approximated with equation (1) what is a Basquin formula for $\mathrm{S}-\mathrm{N}$ presentation and approximation (NovÝ F. et al. 2012).

$$
\sigma_{a}=\sigma_{f} \times N_{f}^{-b}
$$

Where:

$\sigma_{a}$ is stress amplitude, $\sigma_{f}{ }^{\prime}$ is a coefficient of fatigue strength and $b$ is lifetime curve exponent. For AISi9Cu3 cast alloy was Basquin formula for S - N (2) and for IN718 (3):

$$
\begin{gathered}
\sigma_{a}=618.67 \times N_{f}^{-0.137} \\
\sigma_{a}=1470 \times N_{f}^{-0.0795}
\end{gathered}
$$




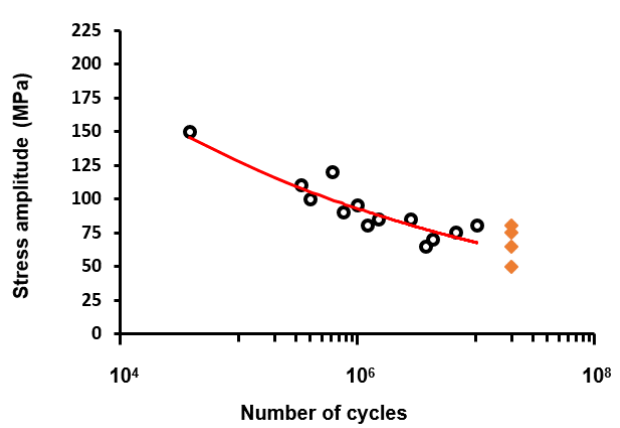

a) AlSi9Cu3 cast alloy

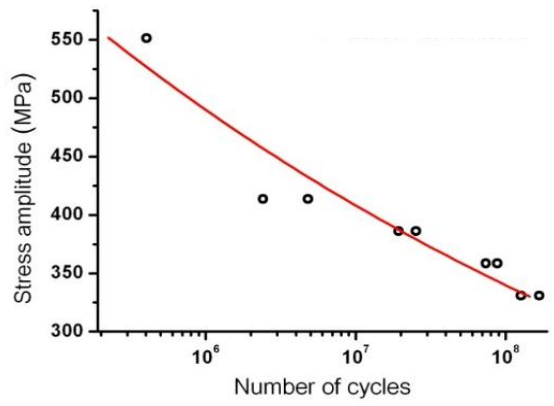

b) IN718

Fig. 2. Fatigue tests $\mathrm{S}-\mathrm{N}$ curves, room temperature, $\mathrm{R}=-1$

From measured $\mathrm{S}-\mathrm{N}$ curve is clearly seen that the fatigue life increases with decreasing stress amplitude and the $\mathrm{S}-\mathrm{N}$ curve appears to continuously decline as the life extends. The results of fatigue test shows that the range of fatigue lifetime for $2 \times 10^{7}$ cycles was from 50 to $80 \mathrm{MPa} \rightarrow$ average fatigue lifetime for $2 \times 10^{7}$ cycles was about $67.5 \mathrm{MPa}$ (Fig. 2a) in AISi9Cu3 experimental alloy. The longest fatigue life of the fractured specimens of IN718 is $1.679 \times 10^{8}$ cycles, which takes 2 hours and 19 minutes of fatigue testing at frequency of $20.13 \mathrm{kHz}$ (Fig. 2b). The test result can be regarded as the direct evidence of fact that IN718 may still fracture in the VHCF regime at room temperature. These results also confirmed higher fatigue lifetime of IN718 comparison to AISi9Cu3. The increasing was about 4 times higher in IN718 as in AISi9Cu3 cast alloy (Fig. 2).

\subsection{Fractography analysis of fatigue fracture}

The process of fatigue generally consists of three stages, Fig. 3, (Bokưvka, et al 2014; Palček, et al. 2003; Nový, et al. 2012): crack initiation (stage I); progressive ("stable") crack growth across the component (stage II); and a final sudden fracture of the remaining cross section of the component (stage III). Stages I and II are also called fatigue region. Fatigue fracture or failure of material under stress is significantly lower than yield stress. Fatigue crack growth occurs by a shear mechanism in the direction of the primary slip system over a few grains. The crack propagates on planes oriented at approximately $45^{\circ}$ to the stress axis (Rodopoulos, 2009).

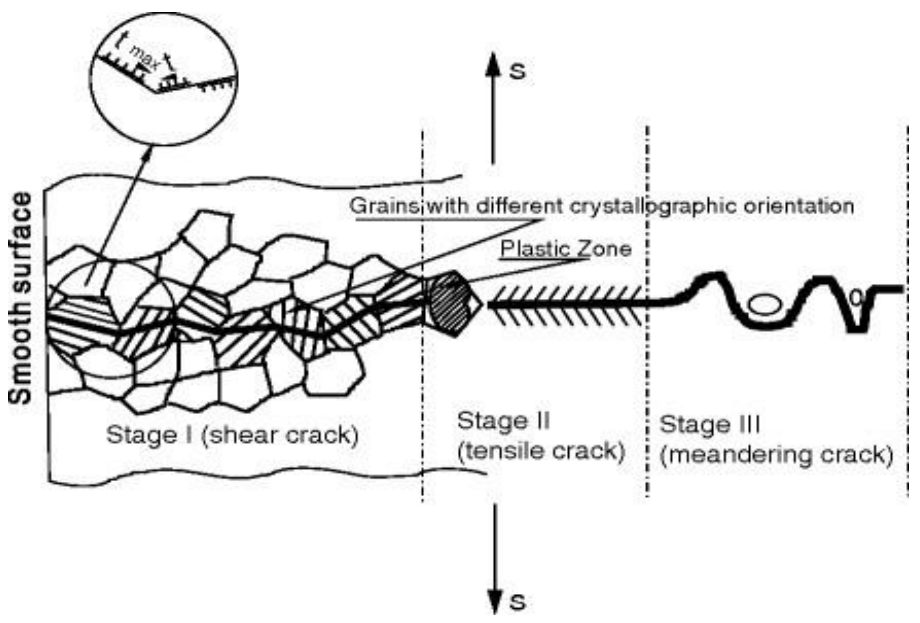

Fig. 3. Three stages of fatigue fracture.

Source: (Rodopoulos,2009) 
The preferred mechanism of initiation will, therefore, depend on the microstructure and manufacturing process of the material, the type of loading, and shape of the component. To the components which cause fatigue fracture belongs: microscopic material defects, such as second-phase particles, inclusions or precipitates, surface notches, and machining marks; microstructural features, such as grain boundaries, triple points, and twin boundaries and also environmental effects like pitting corrosion a local concentration of stress which may exceed the yield strength of the material is developed (Rodopoulos, 2009).For these reasons the SEM observation of fatigue fracture were used.

Within the fatigue tests boundaries we established that high stress amplitude causes a small fatigue region and a large region of final static rupture (Fig. 4a,b, Fig. 6a,b). The SEM metallographic analysis of fracture surfaces confirmed the key role of porosity, which was the point of fracture crack initiation in experimental samples (Stage I). The initiation sites were pores (casting defects) of irregular shape, near the surface of the samples, initiating the crack propagation (Fig. 4c, d). The same samples have more initiation sites as shown in Fig. 4c.

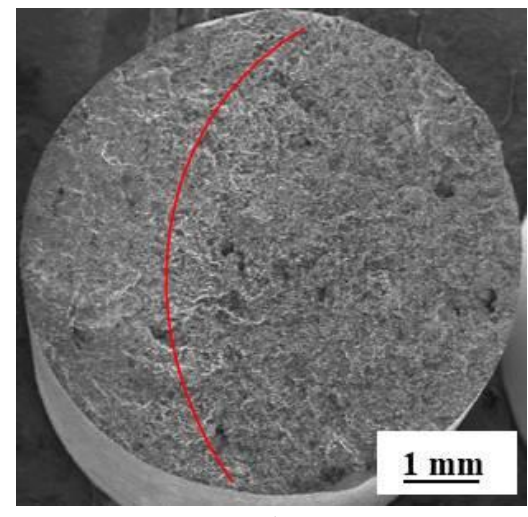

a)

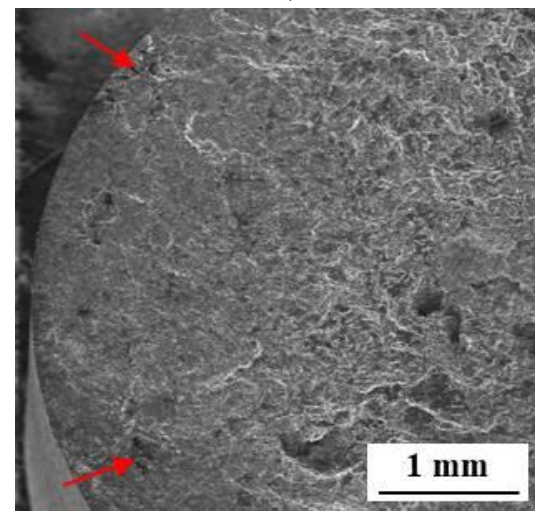

c)

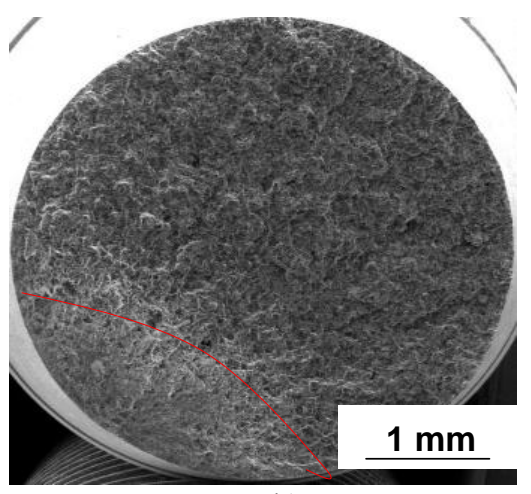

b)

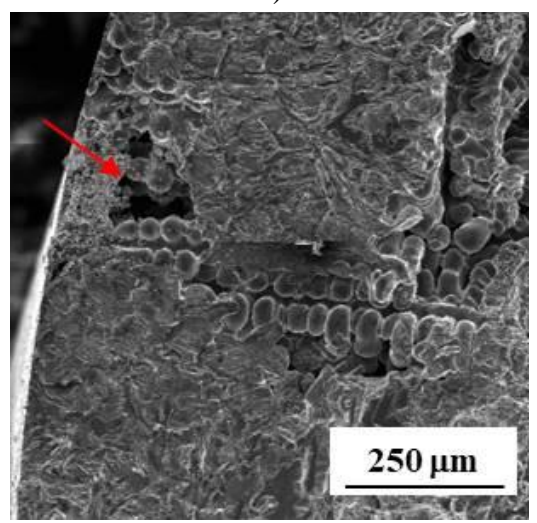

d)

Fig. 4. Fractography analysis of fatigue fracture on aluminum samples

a) fracture surface with large fatigue region;

b) fracture surface with small fatigue region; c) d) the initiation sites (Stage I)

The initiation sites for samples were more concentrated at one point with the decreasing stress amplitude. Stages II and III for samples: The area of the stable crack propagation (Stage II) is characterized by transcrystalline fatigue fracture of $\alpha$ phase with smooth areas (Fig. 5a, b). The smooth areas were identified as Fe-rich phases and Si particles using SEM (BSE) and EDX analysis. The typical aspect of 
fatigue - striations - were observed only in few isolated cases in an area between Stage II and Stage III of fatigue fracture (Fig. 5c). The last stage (Stage III) consisted of a transcrystalline ductile fracture with plastic strain ranges of Al matrix ( $\alpha$-phase) and transcrystalline cleavage fractures of Si particles and also brittle iron intermetallic phases (Fig. $5 d$, e, f). The transcrystalline ductile fracture is related to the $\mathrm{Cu}-$ rich intermetallic phases, too (Fig. 5f).

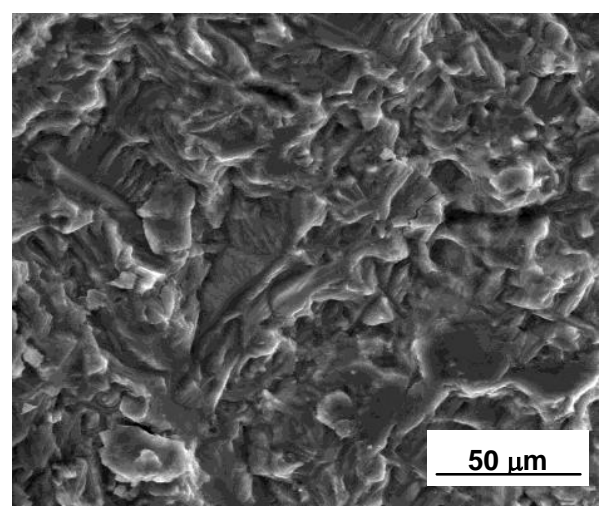

a)

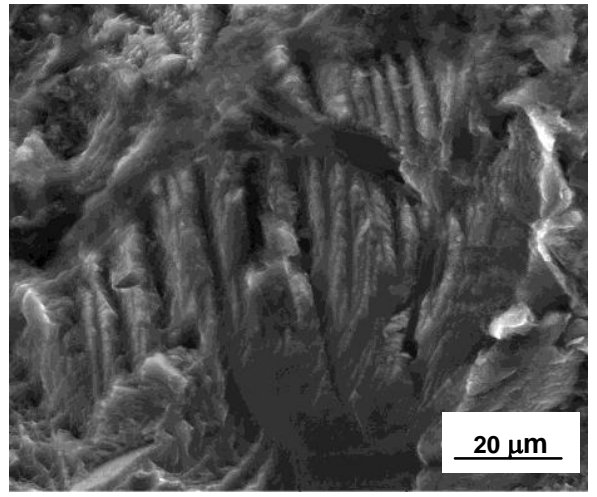

c)

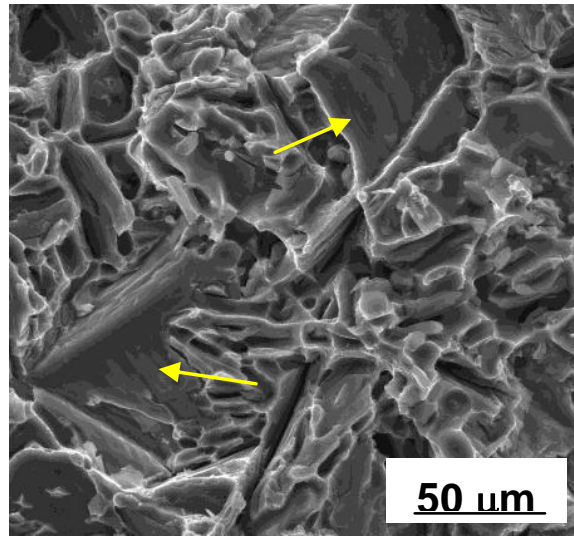

e)

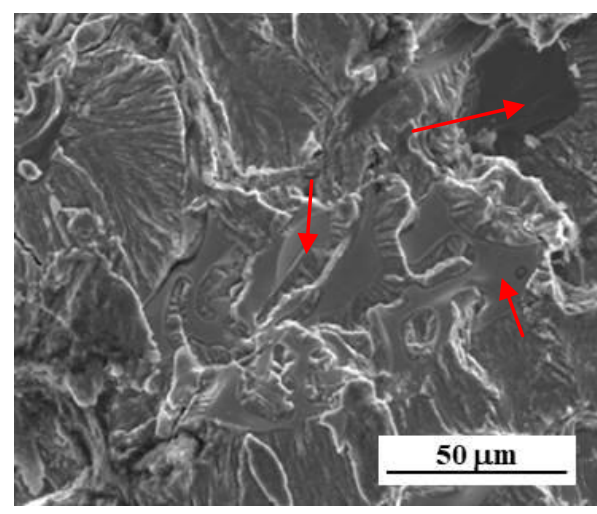

b)

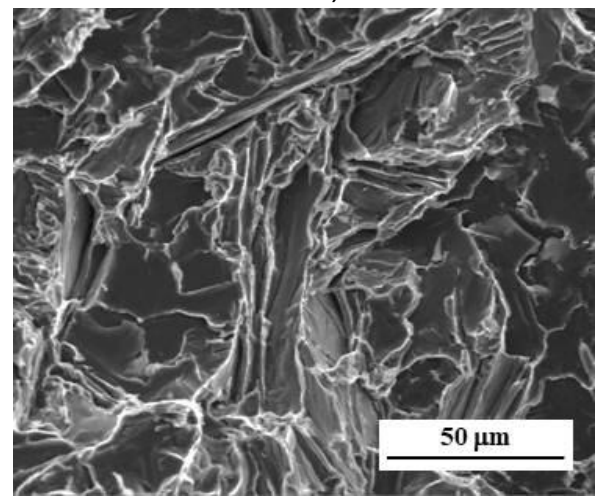

d)

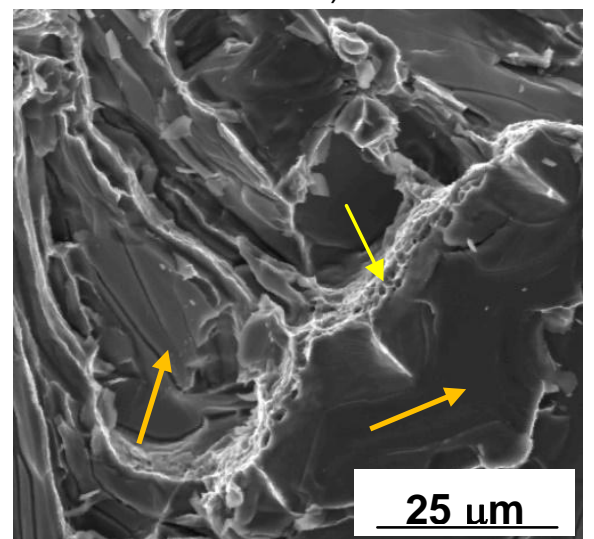

f)

Fig. 5 Fractography analysis of fatigue fracture on aluminum samples a) the fatigue fracture surface (Stage II); b) smooth areas - Fe-rich phases and $\mathrm{Si}$ particles fatigue region; c) the area between Stage II and III; d) the static fracture (Stage III); e) smooth areas - Fe-rich phases, static rupture; f) smooth areas - Si particles and fracture Cu-rich phases, static rupture

For IN718 at high stress levels as shown in Fig. 6a, fatigue crack initiated from multiple initiation sites and resulted into a very small tensile final fracture area (Stagel). With decreasing stress level, the number of initiation sites decreases, Fig. $6 \mathrm{~b}$, controlled by 
crystallographic slip at surface grains and static tensile final fracture area increases. Fracture due to a single fatigue crack occurs for specimens with longer fatigue life (> $2.414 \times 10^{6}$ cycles, e. g. Fig. 6 b). In this case fatigue crack takes place at the specimen surface where can be seen a massive initiation point, probably oxide, resulting into a significant crack as seen in Fig. 6c. After initiation fatigue crack propagates with transcrystalline mechanism with typical striations, indicates the stable crack propagation as reported in Fig. 6d and 6e (Stage II). At higher stress level, Fig. 6e, a few secondary cracks have appears whose are perpendicular to main fatigue crack propagation and probably are situated at grain boundaries. In Fig. $6 f$ is reported a change in micro-mechanism of fracture, very sharp border with secondary crack, between typical fatigue crack propagation and classical transcrystalline ductile dimpled fracture mechanism in the tensile final fatigue region (Stage III).

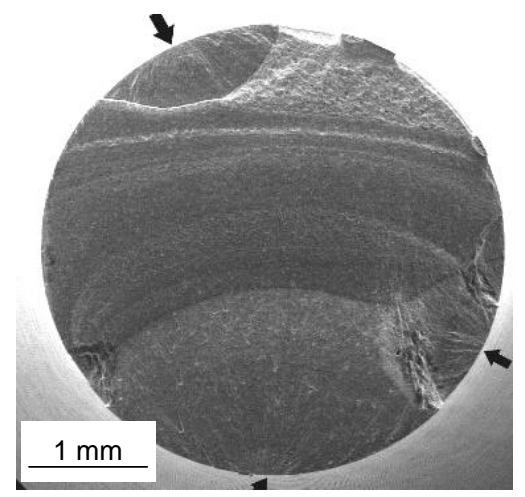

a)

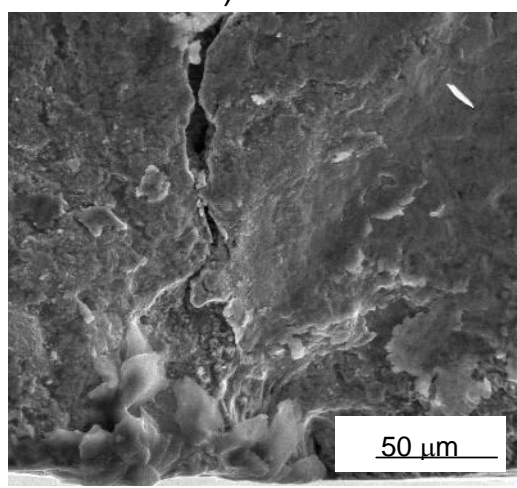

C)

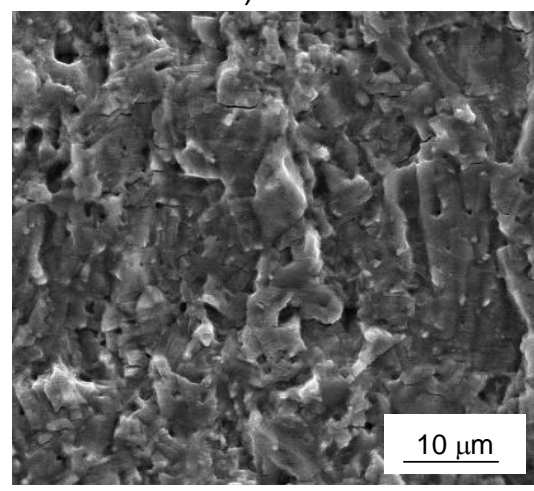

e)

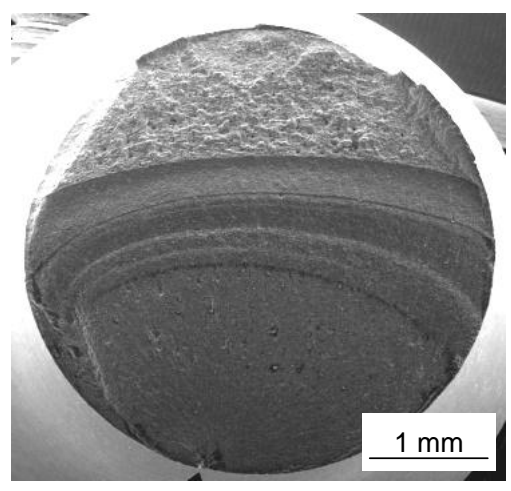

b)

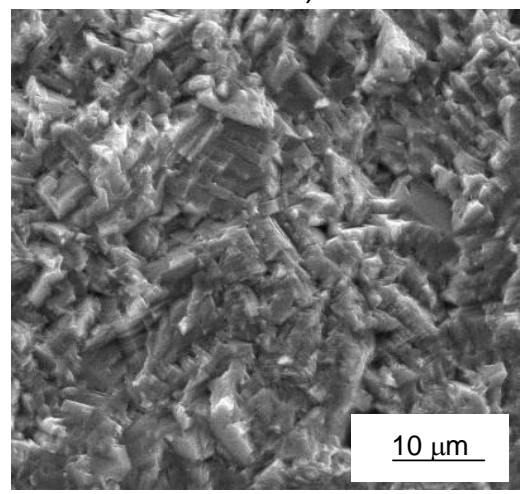

d)

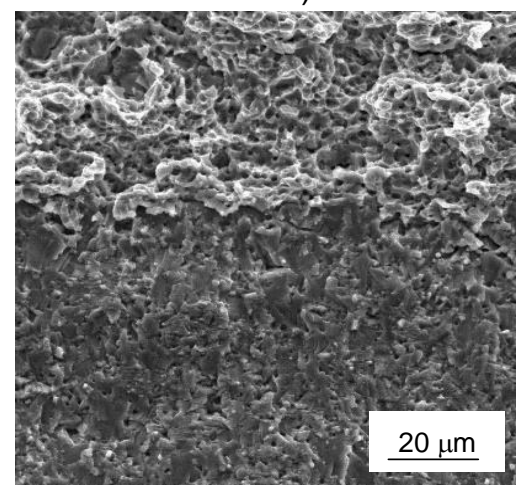

f)

Fig. 6. Fractography analysis of fatigue fracture surfaces of IN 718

a) fracture surfaces with large fatigue region; b) fracture surfaces with small fatigue region;

c) the initiation site; d) e) the fatigue region; f) the static rupture (Stage III). 


\section{CONCLUSION}

The present study describes fatigue properties of two different material uses in transport industries. The results confirmed dependence of fatigue properties from microstructure of experimental materials:

- The results of fatigue lifetime shows that AISi9Cu3 cast alloy without grain refinement, modification and heat treatment have average value of fatigue lifetime for $2 \times 10^{7}$ cycles about $67.5 \mathrm{MPa}$. The predicted value of fatigue lifetime for $10^{7}$ cycles for experimental material was $68 \mathrm{MPa}$ according to Basquin`s equation obtained from the diagram. The casting from aluminum alloys are mostly influenced by the amount of hydrogen because, the pores (casting defects) initiated for fatigue crack propagation in AISI9Cu3 cast alloy. The hard and brittle eutectic Si particles and $\mathrm{Fe}$ - rich intermetallic phase cause transcrystalline and intercrystalline fatigue fracture and transcrystalline cleavage fracture; matrix with $\mathrm{Cu}$ - rich intermetallic phases cause transcrystalline fatigue fracture and transcrystalline ductile fracture. The fracture surface of the final rupture is formed from transcrystalline cleavage and ductile fracture. Transcrystalline cleavage fracture was dominant on the fracture surface.

- Using of ultrasonic high frequency $\approx 20 \mathrm{kHz}$ at fatigue testing of IN718 significantly shorten time necessary to get $\approx 10^{8}$ cycles (to run $1.679 \times 10^{8}$ takes 2 hours and 19 minutes instead a number of days at lower frequency). It was proved that alloy is still fracture even after reaching $1.679 \times 10^{8}$ - fatigue limit was not observed. Even after reaching value $10^{8}$ cycles was not observed run-out of specimens. Fractography analysis shows that at higher stress level fatigue crack initiates from a multiple sites and with decreasing of stress amplitude crack initiation sites are reduced into a single one controlled by crystallographic slip at surface grains or massively oxidized areas. After initiation the cracks is propagated by typical transcrystalline mechanism with very fine striations and some secondary cracks perpendicular to major fatigue crack propagation and have been observed at higher levels of stress amplitude and corresponding to grain boundaries. The area of static tensile overload is characterized by ductile dimple morphology.

\section{REFERENCES}

Akca E., Gursel A. 2015. A Review on Superalloys and IN718 Nickel-Based INCONEL Superalloy. Periodicals of engineering and natural science, 3(1), 15-27.

Bokůvka O., Nicoletto G., Guagliano M., Kunz L., Palček P., Nový F., Chalupová M. 2014. Fatigue of Materials at low and high frequency loading, EDIS, first edition, Žilina-Slovakia.

Davis J.R. 2000. ASM Specialty Handbook: Nickel, Cobalt, and Their Alloys, $1^{\text {st }}$ edition, ASM International, Ohio-USA.

Kensington V. 2015. Automobile Industry Aluminum Demand Is Rising (online 5.4.2018 https://marketrealist.com/2015/12/auto-industrys-aluminum-usage-increasing

Kracke A. 2010. Superalloys, the most successful alloy system of modern times-past, present and future. $7^{\text {th }}$ international symposium on Superalloy 718 and derivatives. 13-50.

Nový F., Bokůvka O., Trško L., Chalupová M. 2012. Ultra-high cycle fatigue of materials. International Journal of engineering, Vol. X 2, 231 - 234. 
Palček P., Chalupová M., Nicoletto G., Bokůvka O. 2003. Prediction of machine element durability, Education Aid for multimedia lectures, CETRA, Žilina.

Rodopoulos, C. A. 2009. Fatigue damage map as a virtual tool for fatigue damage tolerance. Virtual testing and predictive modelling, e.Book, 73-104.

Uhričik M., Palček P., Soviarová A., Snopiński P. 2014. Change of internal friction on aluminium alloy with $10.1 \% \mathrm{Mg}$ dependence on the temperature, Manufacturing technology, 14(3), 467-470. 